\title{
Long-Term Properties of Cement-Based Composites Incorporating Natural Zeolite as a Feature of Progressive Building Material
}

\author{
Alena Sičáková, Matej Špak, Mária Kozlovská, and Marek Kováč \\ Faculty of Civil Engineering, Technical University of Košice, Vysokoškolská 4, 04200 Košice, Slovakia \\ Correspondence should be addressed to Matej Špak; matej.spak@tuke.sk
}

Received 9 June 2017; Revised 14 August 2017; Accepted 7 September 2017; Published 18 October 2017

Academic Editor: Prinya Chindaprasirt

Copyright (c) 2017 Alena Sičáková et al. This is an open access article distributed under the Creative Commons Attribution License, which permits unrestricted use, distribution, and reproduction in any medium, provided the original work is properly cited.

\begin{abstract}
This study is aimed at the utilization of natural zeolite as a prospective type of Supplementary Cementitious Material in connection with the innovations of construction solutions through the materials. The influence of zeolite on several properties of cement-based composites is studied. Basic characteristics of input powdery materials as well as the technological parameters of zeolite tested on mortar containing $50 \%$ of cement replacement are presented. The technical parameters of concrete containing 8,13 , and $25 \%$ of cement replacement by zeolite are presented as well. The paper is valuable due to the three-year testing period. The density of the hardened concrete was found to be decreasing with increasing zeolite content. While no significant differences in compressive strength were found after 28 days, differences between individual samples were clear after the long-term period. The presence of zeolite influenced the compressive strength positively in the case of the $8 \%$ and $13 \%$ replacement, while the higher proportion of natural zeolite (25\%) caused lower compressive strength after 28 days but was similar to the reference concrete after three years. A major increase in strength was detected for all samples in the long-term period. It confirms the long-term potential of zeolite for strength improvement.
\end{abstract}

\section{Introduction}

The ordinary Portland cement is one of the most utilized binder materials for the production of building materials. However, its production has negative environmental impact due to the requirement of high amount of energy, production of greenhouse gases, and so on. Utilization of supplementary cementitious materials (SCMs) for the production of cementbased composites can help to significantly minimalize these adverse influences. Additionally, different SCMs bring several types of improvement to composites properties, for example, better workability or durability. Moreover, the costs of concrete can decrease. The incorporation of SCM is a feature of the current advanced concrete and is connected with the modern approaches to concrete production. Thus, it can be successfully involved in the modern methods of construction. Natural zeolite is one of the best-applicable SCMs, mainly due to its pozzolanic activity.
The quality and durability of concrete are strongly dependent on the kind, properties, and dosage of the basic components (cement, water, and aggregates) and the additives and admixtures. The alternative materials play an important role in current concrete technology such as SCMs. Due to the improvement of mechanical properties and durability of concrete, the trend of utilization of SCMs has increased [1-3]. SCMs improve the microstructure of concrete by minimizing its porosity and improving the resistance against the aggressive attack due to their chemical nature $[2,4-7]$. In the standard EN 206 [8], three kinds of Type II additions-fly ash, blast furnace slag, and silica fume-are mentioned, and the conditions of their application to the concrete are specified.

The other kinds of addition can be used in specific cases of concrete structure exposure. Both zeolite and silica fume are recommended if a chemical attack occurs. The standard [8] defines the kind of addition in accordance with both the 
nature and intensity of chemical environment, but the recommended dosage is not specified in the standard. Therefore, the practical production of concrete can be uncertain. There are a number of studies investigating zeolite as cement supplement (pozzolanic additions) [9-17]. Some results of these studies are ambiguous, as shown below. There is a lack of information on the influence of specific dosage of additions on the longterm properties of the concrete and information about other relevant properties, such as length deformation and water absorption capacity.

Natural zeolites are hydrated aluminosilicates that have high amounts of reactive $\mathrm{SiO}_{2}$ and $\mathrm{Al}_{2} \mathrm{O}_{3}$. Their reactivity is mainly attributed to their highly porous structure, which is related to the large external surface area giving interaction of zeolite with lime [11, 12], ability of ion exchange, and meta-stability, which supports the dissolution of zeolitic crystals and precipitation of hydrated calcium silicates and aluminates during interaction of $\mathrm{OH}^{-}$ions available in the saturated lime solution $[13,14]$.

Researchers have found that the zeolites of different modifications act as pozzolanic additions in concretes; during cement hydration, $\mathrm{CSH}$ and $\mathrm{CAH}$ gel phases increase, which also increases the resistance of Portland cement compositions to acids and sulphate corrosion and increases its durability as well [11].

Regarding the early-age strength, the references are different. According to Yun-Sheng et al., zeolite added at $15 \%$ to the cement mix increases the early-age strength of concrete [15]. Turkish researchers carried out tests on concrete specimens containing $5,10,20$, and $40 \%$ of zeolite. Compressive strength was measured after one, two, seven, and 28 days of curing. The results showed that the concrete specimens with zeolite additive had lower compressive strength compared to the control specimen after 24 hours of curing. The same trend was observed after two and seven days of curing. After 28 days of curing, the compressive strength of specimens containing $5 \%$ of zeolite increased by $6.8 \%$ compared to the control specimens; the compressive strength of the next specimens increased by $15.9 \%, 22.3 \%$, and $4.1 \%$ for specimens containing $10 \%, 20 \%$, and $40 \%$ of zeolite, respectively [16].

According to Ramezanianpour et al. [17], the addition of natural zeolite delays the strength development during the first seven days, after which the concretes containing $10 \%$ of natural zeolite provide almost similar compressive strength compared to that of the reference concretes. The strength of concrete mixtures containing $15 \%$ of natural zeolite, however, is marginally lower than that of the reference concrete. The pozzolanic activity of natural zeolite is significantly high, as most of the pozzolanic reactions occurred between seven and 28 days. The use of natural zeolite leads to considerable reductions in water permeability and capillary absorption for each of the selected water-to-cementitious material ratios. The highest improvements through the use of natural zeolite were observed in the rapid chloride permeability and electrical resistivity tests. The electrical resistivity of concrete samples containing natural zeolite was two to four times better than those of the reference samples. These improvements were more significant for concretes with higher water-tocementitious materials ratios $(\mathrm{w} / \mathrm{cm})$. The electrical resistivity and rapid chloride penetrability of mixtures with 10 and $15 \%$ natural zeolite and $\mathrm{w} / \mathrm{cm}$ of 0.50 was better than that of the reference concrete with $\mathrm{w} / \mathrm{cm}$ of 0.35 , indicating that using $10-15 \%$ of natural zeolite was more effective in improving permeability than reduction in $\mathrm{w} / \mathrm{cm}$ from 0.50 to 0.35 . The depth of carbonation increases with the use of natural zeolite. While the reduction of chloride penetration enhances the concrete resistivity against corrosion, the increased carbonation results in the opposite performance. Study of the SEM images shows significant improvements in porosity of the studied pastes through the use of natural zeolite. In addition, studying the images taken from transition zone reveals that natural zeolite enhances the structure of the transition zone favourably. The calcium hydroxide content is considerably reduced by the use of natural zeolite as an SCM, which results in the production of secondary C-S-H.

According to Vejmelková et al. [18], both the bulk and the matrix density of cement-based composites decrease with increase in the zeolite supplementary. Poon et al. [19] also state that $15 \%$ replacement of zeolite results in lower porosity, while a higher replacement level (25\%) increases the porosity at all studied ages.

The drying shrinkage of products made with Portlandpozzolan cements is dependent on the hydration products and water demand of the mixtures. Although tests should be conducted to determine the drying shrinkage of Portland cement and natural pozzolans combinations, there is a scarcity of studies in this field [20]. Jana [21] investigates the effects of using 10,20, and 30\% of zeolite as an SCM. He observes that drying shrinkage of zeolite mixtures at 10 and $20 \%$ of Portland cement replacement levels is similar or slightly higher than that of the control mixture, whereas by using $30 \%$ of zeolite, the drying shrinkage is about $20 \%$ higher than the control mixture. Moreover, Kasai et al. [22] examined drying shrinkage for the mortars blended with clinoptilolite and mordenite. Both clinoptilolite and mordenite blended mortars experienced higher shrinkage than the control one.

It is reported that although natural zeolite reduces the slump of concrete, it can prevent bleeding and segregation. Regarding hardened concrete, natural zeolite increases compressive strength due to its pozzolanic property. Moreover, it enhances the durability of conventional concrete by reducing concrete permeability and, mainly, by improving resistance to alkali-aggregate reaction [23]. According to Najimi et al. [24], natural zeolite can be properly used as an SCM in normally consolidated concrete, considering the environmental protection and sustainable development. Chan and Ji [25] report that the pozzolanic reactivity of natural zeolite is between that of silica fume and fly ash.

This paper is aimed at the utilization of zeolite as a perspective kind of SCM and its influence on the long-term (up to three years) properties of concrete, since there is a lack of information about the long-term properties. Most reports are oriented towards the 28-day properties, or eventually up to one year, because of the challenges of long-term research. However, the pozzolanic additions need a longer time to develop their properties in the construction due to the slower progress of pozzolanic hydration processes. The short-term values of properties could be misleading. 
TABLE 1: Chemical composition and particle size characteristics of binders.

\begin{tabular}{|c|c|c|c|c|c|c|c|c|}
\hline Binder & $\mathrm{SiO}_{2}$ & $\mathrm{CaO}$ & $\begin{array}{l}\mathrm{Fe}_{2} \mathrm{O}_{3} \\
\text { [\% wt.] }\end{array}$ & $\mathrm{Al}_{2} \mathrm{O}_{3}$ & $\mathrm{MgO}$ & $\begin{array}{c}\mathrm{CaO} / \mathrm{SiO}_{2} \\
{[-]}\end{array}$ & $\begin{array}{c}d(0.5) \\
{[\mu \mathrm{m}]}\end{array}$ & $\begin{array}{c}d(0.9) \\
{[\mu \mathrm{m}]} \\
\end{array}$ \\
\hline OPC (CEM I $42.5 \mathrm{~N})$ & 20.34 & 64.1 & 2.99 & 2.97 & 9.03 & 3.150 & 26.68 & 67.87 \\
\hline Natural zeolite & 78.75 & 3.50 & 1.73 & 11.6 & 1.16 & 0.040 & 20.68 & 91.97 \\
\hline Silica fume & 97.00 & 0.70 & 1.50 & 1.10 & - & 0.007 & 0.226 & 8.647 \\
\hline
\end{tabular}

Comprehensive results for zeolite, including basic characteristics (chemical composition and particle size distribution), technological parameters (mixing water demand, initial setting time, activity index, and relative linear deformation), and technical parameters of concrete incorporating zeolite (density, compressive strength, and total water absorption) are presented in the paper. For comparison, addition of silica fume is presented as well.

\section{Materials and Methods}

The main scope of the experiment is to observe the longtime technical parameters (density, compressive strength, and water absorption) of zeolite-based concrete and to assess the possibility of the practical utilization of natural zeolite for the production of progressive building material.

2.1. Materials Characteristics. Three types of mineral binders are used in the experiment. Ordinary Portland cement (OPC) class CEM I $42.5 \mathrm{~N}$ came from Turňa nad Bodvou, Slovakia, natural zeolite (NZ) came from Lehôtka pod Brehmi, Slovakia, and silica fume (SF) came from Istebné, Slovakia.

The chemical composition of ordinary Portland cement, natural zeolite, and silica fume was determined through Xray fluorescence analysis (XRF). SPECTRO iQ II (Ametek, Germany) with silicon drift detector (SDD) with resolution of $145 \mathrm{eV}$ at 10,000 pulses was used for the analysis. The primary beam was polarized using Bragg crystal and Highly Ordered Pyrolytic Graphite (HOPG) target. The samples were measured at 300 and $180 \mathrm{~s}$ at voltage of $25 \mathrm{kV}$ and $50 \mathrm{kV}$ and current of 0.5 and $1.0 \mathrm{~mA}$ in a helium atmosphere by using the standardized method of fundamental parameters for cements or liquids. The chemical compositions of binder solids are listed in Table 1.

The particle size distribution of binder solids was determined using a laser granulometric analyser (Mastersizer 2000; Malvern Instruments Ltd, UK). The parameters of grain size distribution are characterized by $d(0.5)$ and $d(0.9)$ medians, which are also listed also in Table 1 . The curves of particle size distribution of binders are shown in Figures 1-3, respectively.

The differences in the particle size of binding materials are evident and in accordance with their character. Results also inform indirectly about the specific surface area in terms of mutual comparison: the smaller the particle size, the larger the specific surface area.

2.2. Technological Characterization of Natural Zeolite. Technological characterization (water demand for standard consistency, initial setting time, activity index, and relative linear

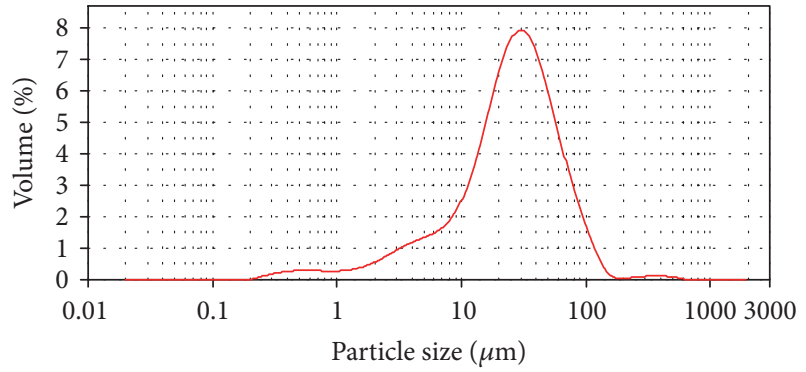

Figure 1: Particle size distribution of OPC.

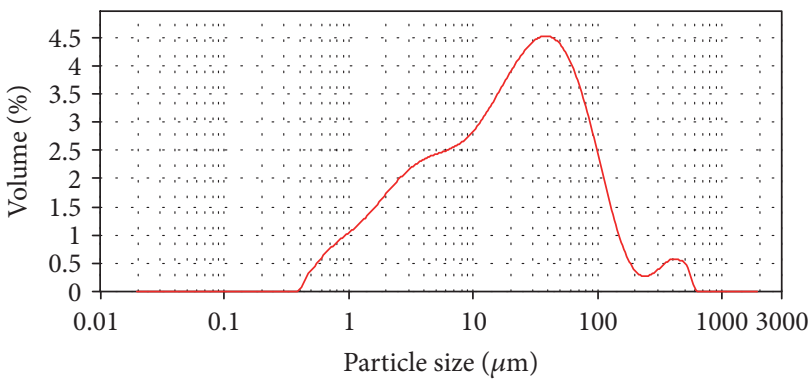

FIGURE 2: Particle size distribution of natural zeolite.

deformation) of natural zeolite was investigated. Both the water demand and initial setting time were tested on pastes composed of $50 \%$ of OPC and $50 \%$ of NZ and pastes consisting of OPC only, while the water-to-binder ratio was 0.5 . Both the strength activity index and relative linear deformation were tested on mortars consisted of $1350 \mathrm{~g}$ of normalized silica sand, $500 \mathrm{~g}$ of binder, and $225 \mathrm{~g}$ of water, while two samples with different binder composition were tested. The control mixture contained $100 \%$ of OPC and research mixture contained $50 \%$ of OPC and $50 \%$ of NZ.

The water demand for standard consistency (the consistency that will permit the distance between plunger of Vicat apparatus and base-plate of $4-8 \mathrm{~mm}$ ) and the initial setting time (the elapsed time, measured from zero to the time at which the distance between the needle and the base-plate is 3-9 $\mathrm{mm}$ ) were measured using standard methods for testing cements (according to [26]).

The activity index was found in accordance with [27]. Here, the activity index refers to the ratio of the average compressive strength of SCM-based mortar and the reference cement-based mortar at the designated ages. Compressive strength was tested in accordance with [28].

The deformation changes of tested mortars were measured through active linear deformation [mm], using the 


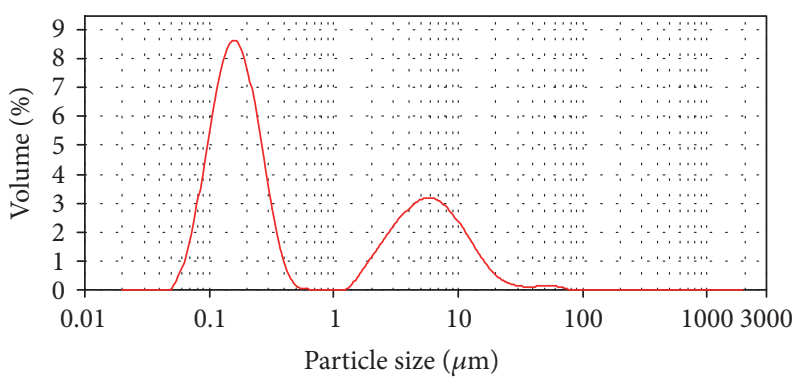

FIGURE 3: Particle size distribution of silica fume.

length comparator, while three samples were measured for each recipe. The relative linear deformation was then calculated as the ratio of the active linear deformation $[\mathrm{mm}]$ to the actual length of the sample [mm]. Specimens of dimensions $40 \times 40 \times 160 \mathrm{~mm}$ were measured during 60 days at regular intervals. During this time, samples were kept in standard wet conditions $\left(20^{\circ} \mathrm{C}\right.$ temperature and water curing).

2.3. Physical-Mechanical Properties of Natural Zeolite-Based Concrete. The mineral binders (OPC, NZ, and SF) were used for concrete preparation. Natural normal-weight fine and coarse aggregates of fractions $0 / 4,4 / 8$, and 8/16 (NFA-0/4, NCA-4/8, NCA-8/16) were used. The superplasticizer based on polycarboxyl ether (PCE) was used to obtain optimal consistence together with tap water.

The experiment was focused on testing the concrete mixture designed by the acceptance of the standard recommendations for the composition for aggressive exposure. The recipe of the reference concrete was designed to achieve the compressive strength corresponding to C 35/45 strength class (according to [8]). Water-to-binder ratio (w/b) was 0.45 and cement content was $360 \mathrm{~kg}$ per $1 \mathrm{~m}^{3}$ of fresh concrete. Natural zeolite was applied in varying replacement percentages to cement $(8 \%, 13 \%$, and $25 \%$ by weight). For directly showing binder modification by well-known silica fume, it was decided to use the combination of $8 \%$ of zeolite and $8 \%$ of SF. The materials and compositions of the tested concretes are given in Table 2.

The samples of cubes shape with dimensions $150 \times 150$ $\times 150 \mathrm{~mm}$ were prepared with standard methods. Specimens were released after one day and consequently cured in water under laboratory conditions until the tests execution. The standard tests (density, compressive strength, and water absorption) were executed after 28 days and the compressive strength after 365, 730, and 1095 days (one, two, and three years) according to [29-31].

\section{Results and Discussion}

3.1. Technological Characterization of Natural Zeolite. The water demand for standard consistency, initial setting time, and activity index of mortars are listed in Table 3. The consistent results comparing $[17,32,33]$ have been found, in fact, to determine the expansion of water demand (probably due to a larger specific surface area) and to increase the setting time increasing of zeolite-blended mortars. The presented

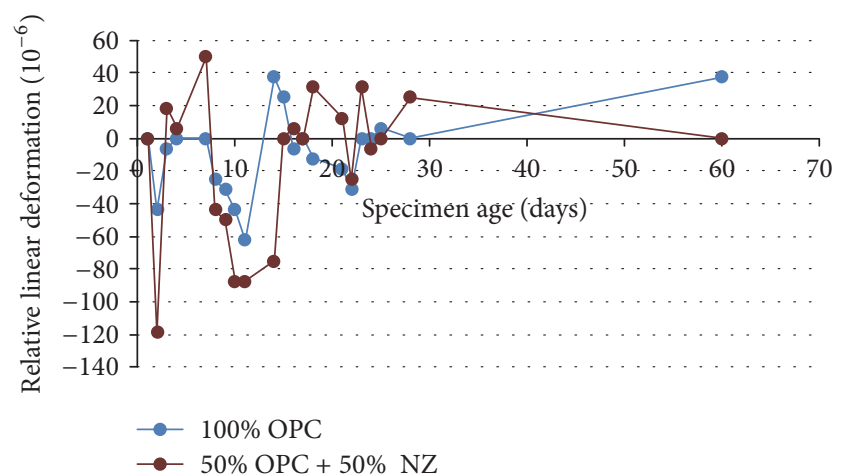

FIGURE 4: Relative linear deformation of the $100 \%$ OPC and $50 \%$ $\mathrm{OPC}+50 \% \mathrm{NZ}$ mortar.

results for the zeolite paste also refer to the higher need for water to obtain the standard consistency. The initial setting time is practically three times longer than that of cement. Activity index after seven days (20.4) and 28 days (48.5\%) shows low increase in strength at an early age and high cement replacement (50\%).

Deformation changes in tested mortars are given through 60-day development of relative linear deformation, as shown in Figure 4.

Results of drying shrinkage presented worldwide are often not consistent because of nonuniform methods, apparatus, and curing conditions; these results are discussed in both positive and negative ways $[21,24,34]$. Here, the method of relative linear deformation is given for the direct comparison of two kinds of mortars cured under the same conditions, while the effect of zeolite is clearly visible. The relationship between the linear deformation changes and the risk of cracking is generally known.

The linear deformations of both samples are quite active up to 60 days, while the linear deformation of zeolite samples is somewhat larger than that of the cement-only samples; the values ranges of $\mathrm{NZ}$ and OPC based samples are -120 to +50 and -62 to +37 , respectively. Jana [21] reports similar results when using $30 \%$ of zeolite as SCM; he obtained about $20 \%$ higher drying shrinkage than that of control mixture without zeolite.

\subsection{Physical-Mechanical Properties of Natural Zeolite-Based Concrete}

3.2.1. Density. The density of hardened concrete is referred as one of the durability-related properties, due to the porosity and permeability context. Concrete porosity is inversely proportional to density. Usually, the concrete permeability increases with an increase in porosity and decreases with an increase in density. The relation between permeability and porosity depends on the pore system properties. Lower concrete porosity leads to reduction in permeability and consequently in better durability. A very highly impermeable concrete reduces or eliminates the ingress of water and other aggressive chemicals and gases. This leads to improved concrete durability due to avoided expansive reactions, which can occur in the presence of these aggressive agents [35]. 
TABLE 2: The recipes of concrete mixtures. Components proportion was calculated for $1 \mathrm{~m}^{3}$ of fresh concrete.

\begin{tabular}{lcccccccrrr}
\hline Mixture & $\begin{array}{c}\text { OPC } \\
{\left[\mathrm{kg} \cdot \mathrm{m}^{-3}\right]}\end{array}$ & $\begin{array}{c}\mathrm{NZ} \\
{\left[\mathrm{kg} \cdot \mathrm{m}^{-3}\right]}\end{array}$ & $\begin{array}{c}\text { SF } \\
{[\%]}\end{array}$ & $\begin{array}{c}\left.\mathrm{kg} \cdot \mathrm{m}^{-3}\right] \\
{[\%]}\end{array}$ & $\begin{array}{c}\mathrm{NFA}-0 / 4 \\
{\left[\mathrm{~kg} \cdot \mathrm{m}^{-3}\right]}\end{array}$ & $\begin{array}{c}\mathrm{NCA}-4 / 8 \\
{\left[\mathrm{~kg} \cdot \mathrm{m}^{-3}\right]}\end{array}$ & $\begin{array}{c}\mathrm{NCA}-8 / 16 \\
{\left[\mathrm{~kg} \cdot \mathrm{m}^{-3}\right]}\end{array}$ & $\begin{array}{c}\text { PCE } \\
{\left[\mathrm{kg} \cdot \mathrm{m}^{-3}\right]}\end{array}$ & $\begin{array}{c}\mathrm{w} / \mathrm{b}^{*} \\
{[-]}\end{array}$ \\
\hline V0 & 360 & - & - & - & - & 825 & 235 & 740 & 0.8 \\
VZ1 & 330 & 29 & 8 & - & - & 825 & 235 & 740 & 0.45 \\
VZ2 & 313 & 47 & 13 & - & - & 825 & 235 & 740 & 0.8 \\
VZ3 & 270 & 90 & 25 & - & - & 825 & 235 & 740 & 0.45 \\
VZ-SF & 302 & 29 & 8 & 29 & 8 & 825 & 235 & 740 & 0.45 \\
\hline
\end{tabular}

${ }^{*}$ Using the $k$-value $=2$ for silica fume in accordance with EN 206.

TABLE 3: Technological parameters of zeolite comparing to cement.

\begin{tabular}{lcccc}
\hline Binder & $\begin{array}{c}\text { Water demand } \\
{[\%]}\end{array}$ & $\begin{array}{c}\text { Initial setting time } \\
{[\text { min. }]}\end{array}$ & $\begin{array}{c}\text { 7-day activity index } \\
{[\%]}\end{array}$ & $\begin{array}{c}\text { 28-day activity index } \\
{[\%]}\end{array}$ \\
\hline OPC & 100.00 & 110 & 100 & 100 \\
$50 \%$ OPC $+50 \% \mathrm{NZ}$ & 126.62 & 320 & 20.4 & 48.5 \\
\hline
\end{tabular}

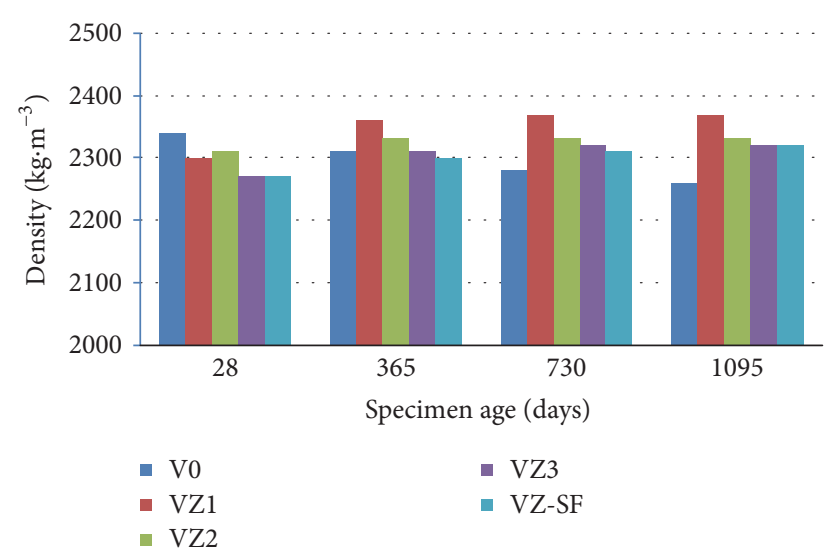

FIGURE 5: Density of hardened concretes after different time of hardening.

The results of density measurement are summarized in Figure 5. Values at 28 days and three years of setting and hardening ranged from 2270 to $2340 \mathrm{~kg} \cdot \mathrm{m}^{-3}$ and from 2260 to $2370 \mathrm{~kg} \cdot \mathrm{m}^{-3}$, respectively. The density of all concretes increased during the time, excluding the concrete V0. The highest growth of density was found between measurements after 28 and 365 days - that is, during the first year of hardening. The density increased during the later stage only gradually. Concrete V0 obtained the highest density of all after 28 days but the lowest at the end of the experiment. Concrete VZ1 obtained highest density after one year and also in later stages. The amount of zeolite proportionally affected the density; thus, the higher dosage of zeolite caused the lower concrete density. This is in contrast to some research $[36,37]$, but, there, the zeolite content was up to $10 \%$. According to Vejmelková et al. [18], both the bulk and matrix densities of the cement-based composites decrease with increase in the zeolite supplementary. Also, Poon et al. [19] observe that $15 \%$ replacement of zeolite resulted in lower porosity (affecting density), but a higher replacement amount (25\%) increased the porosity at all the studied ages. Based on those comments

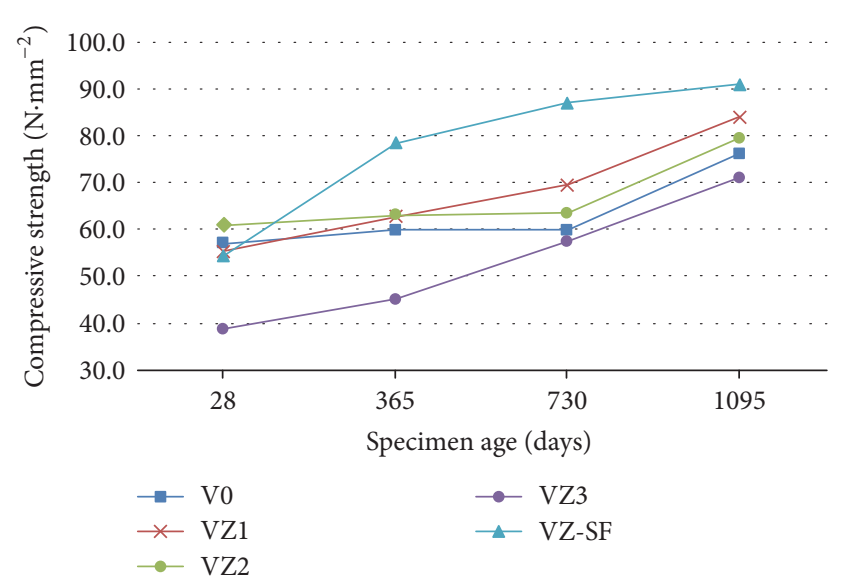

FIGURE 6: Time dependence of compressive strength of hardened concretes.

and our results, the decrease in density can be attributed to the increase in zeolite amount.

The long-term results (one-, two-, and three-year) of all concretes incorporating the natural zeolite are higher than that of the OPC sample (V0), unlike the 28-day values. In this case, the results are lower and do not show the clear dependence on the amount of zeolite. This is clearly visible just after the long-term period. The presence of zeolite manifests itself differently over a longer period of setting and hardening of concrete.

Silica fume in combination with zeolite (concrete VZ-SF) decreased the density significantly compared to the reference concrete (V0) after 28 days. On the other hand, the density of VZ-SF was about $2.6 \%$ higher than V0 after three years.

3.2.2. Compressive Strength. The compressive strength was measured on $150 \mathrm{~mm}$ cubes after 28, 365, 730, and 1095 days of hardening. The time-development of compressive strength is shown in Figure 6. Generally, compressive strength of all concretes increased during the time, as also reported in previous research $[17,24]$. The values after 28 days of 
setting and hardening ranged from 40 to $60 \mathrm{MPa}$, while values after three years ranged from 70 to $90 \mathrm{MPa}$. The initial reference strength (after 28 days) was almost the same for all concretes except VZ3. In the case of VZ3, the strength development was slower because of the high dosage of zeolite in the binder (25\%). The early strength of concrete is commonly supplied by the hydration of $\mathrm{CaO}$ and silicates from cement clinker, while the pozzolanic activity of zeolite later influences the strength. The $\mathrm{CaO} / \mathrm{SiO}_{2}$ ratio of the zeolite used was under 0.5 (Table 1), which refers to its pozzolanic nature. It was in accordance with results from Ramezanianpour et al. and others $[17,36]$. The amount of zeolite in total binder influenced the compressive strength, especially after two and three years of hardening. Concretes VZ1 and VZ2 with $8 \%$ and $13 \%$ of zeolite supplementary achieved about $16.4 \%$ and $6.2 \%$ higher compressive strength compared to the reference concrete after two years and $10.4 \%$ and $4.5 \%$ after three years, respectively. Concrete VZ3 with $25 \%$ zeolite supplementary obtained about $3.8 \%$ and $6.7 \%$ lower compressive strength compared to sample V0 after two and three years, respectively. According to Valipour et al. [38], the optimal content of zeolite to obtain highest compressive strength is $10 \%$.

The significant increase in the compressive strength of all concretes was observed in the long term (three-year period). It confirms the long-term potential of natural zeolite to improve the mechanical properties. The positive change in strength was observed between 28-day and 3-year measurements, following the increase of about $33 \%, 53 \%, 30 \%, 83 \%$, and $67 \%$ for concretes V0, VZ1, VZ2, VZ3, and VZ-SF, respectively. The concrete VZ3 achieved the most significant increase in compressive strength during the monitored period.

The silica fume significantly influenced the compressive strength of concrete. While the strength of VZ-SF sample after 28 days was similar to that of the other samples, the longterm strength values after forwarding periods were much higher. It is also evident that the strength development shows convex behaviour for all VZ concretes and concave behaviour for only VZ-SF concrete. Thus, the compressive strength of SF concrete increased faster than zeolite-based ones, but the strength of zeolite samples grew faster at the end of the monitored period.

The activity index was calculated as a relation between compressive strength of the related concrete and the reference concrete (VZ-/V0) after three years of hardening. This value characterizes the improvement or deterioration of zeolitebased concrete compared to the control one. It was 1.1, 1.0, 0.9, and 1.2 for samples VZ1, VZ2, VZ3, and VZ-SF, respectively. As expected, the higher zeolite content in binder caused lower compressive strength against the reference concrete.

With the exception of VZ-3, the long-term results (one-, two-, and three-year) of all concretes incorporating the natural zeolite are higher than that of the OPC sample (V0), except 28-day values. In this case, the results are close to each other and do not show the clear dependence on the amount of zeolite. This is clearly visible just after the long-term period.

3.2.3. Water Absorption. The water absorption of hardened concretes is summarized in Figure 7. Values after 28 days of

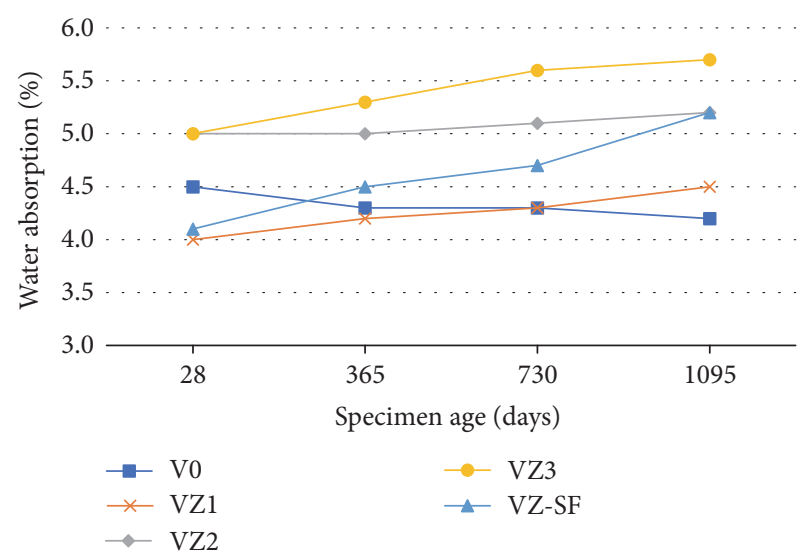

Figure 7: Time dependence of water absorption of hardened concretes.

setting and hardening ranged from 4.0 to $5.0 \%$, while values after three years ranged from 4.2 to $5.7 \%$. The long-term changes in water absorption of zeolite-based concretes were not significant. The relative differences in 28-day and threeyear values were $12.5,4.0$, and $14.0 \%$ for VZ1, VZ2, and VZ3, respectively. The highest increase in water absorption (26.8\%) was found for VZ-SF. Contrary to the control OPC sample (V0), values increase during the three-year period while the amount of zeolite in concrete influences the water absorption negatively. The higher content of zeolite leads to increase in water absorption. It is connected with the water absorption of natural zeolite, which is higher than that of cement [34]. Poon et al. [19] report that the porosity increases due to the higher replacement amount $(25 \%)$ of zeolite at all studied ages; this may also be attributed to the higher absorption ability. It was recognized that the water absorption grew together with density. This result is unexpected, because several research works $[17,24]$ obtained adverse results.

The long-term results (one-, two-, and three-year) of all concretes including the natural zeolite are higher than that of the OPC sample (V0), unlike 28-day values. In this case, VZ1 and VZ-SF obtained lower values. The presence of zeolite manifests itself differently over a longer period of setting and hardening.

\section{Conclusion}

In this paper, the technological properties of natural zeolite and the long-term mechanical properties, density, and water absorption of concrete based on natural zeolite as SCM were evaluated. The results can be summarized as follows:

(i) At high cement replacement (50\%) by the zeolite, the zeolite paste led to a higher demand for mixing water to obtain the standard consistency than that of OPC paste. The initial setting time was practically 2.9 times longer. Strength activity index after 28 days was 48.5\%; this low increase in strength at an early age reflects the slow hydration process.

(ii) The long-term density of all zeolite-based concretes was higher than that of OPC concrete, unlike the 
28-days values. Although the increase in zeolite amount caused the decrease in density, samples incorporating $25 \%$ zeolite achieved higher density than that of OPC in all later ages.

(iii) A major increase in strength was observed for all samples in the long term (three-year period). An increase in the zeolite amount caused a decrease in compressive strength, but the replacement of $8 \%$ and $13 \%$ of cement by natural zeolite brought about an improvement in long-term compressive strength compared to the only-OPC-based concrete. A higher replacement (25\%) caused a decrease in strength after 28 days of setting and hardening; however, significant positive change $(83 \%)$ was observed during the three-year period. This confirms the long-term potential of zeolite to improve the strength. Silica fume, in combination with natural zeolite, significantly improved the strength.

(iv) Long-term changes in water absorption of zeolitebased concretes were not significant, up to $14.0 \%$ in relative difference (26.8\% for VZ-SF). Except for the V0 sample, values were increasing during the threeyear period, while the higher amount of zeolite in concrete negatively influenced the water absorption.

(v) Generally, the long-term properties of zeolite-based concrete are different from that of 28-day properties, while both the density and compressive strength are influenced positively. The differences in concretes composition are manifested after a longer time, when the results are ordered more clearly and show a better sequence dependence on the sample's composition.

The results demonstrate the long-term potential of SCMs for the improvement of the concrete properties, which are important for the long-term role of concrete in the structure.

\section{Conflicts of Interest}

The authors declare that they have no conflicts of interest.

\section{Acknowledgments}

This article has been carried out within the project ITMS "Center of Excellent Integrated Research of Progressive Building Constructions, Materials and Technologies" no. 26220120037 and also presents a partial research result of project VEGA-1/0677/14 "Research of Construction Efficiency Improvement through MMC Technologies."

\section{References}

[1] K. Obla, C. Lobo, and L. Lemay, "Specifying Concrete for Durability".

[2] P. C. Aïtcin, High-Performance Concrete, Taylor \& Francis, Abingdon, UK, 1998.

[3] P. Tikalsky, B. Mather, and J. Olek, Concrete Durability, Transp. New Millenium - State Art Futur. Dir., 2000.

[4] M. Najimi, J. Sobhani, and A. Pourkhorshidi, "Durability of copper slag contained concrete exposed to sulfate attack," Construction and Building Materials, vol. 25, no. 4, pp. 1895-1905, 2011.
[5] S. Levy and P. Helene, "Durability of concrete mixed with fine recycled aggregates," Exacta, vol. 5, no. 1, 2007.

[6] K. Byfors, "Influence of silica fume and flyash on chloride diffusion and $\mathrm{pH}$ values in cement paste," Cement and Concrete Research, vol. 17, no. 1, pp. 115-130, 1987.

[7] V. G. Papadakis, "Effect of supplementary cementing materials on concrete resistance against carbonation and chloride ingress," Cement and Concrete Research, vol. 30, no. 2, pp. 291299, 2000.

[8] European Committee for Standardization, “(20025). EN 2061 "Concrete. Part 1:Specification, performance, production and conformity". Brussels".

[9] D. Caputo, B. Liguori, and C. Colella, "Some advances in understanding the pozzolanic activity of zeolites: The effect of zeolite structure," Cement and Concrete Composites, vol. 30, no. 5, pp. 455-462, 2008.

[10] T. Perraki, E. Kontori, S. Tsivilis, and G. Kakali, "The effect of zeolite on the properties and hydration of blended cements," Cement and Concrete Composites, vol. 32, no. 2, pp. 128-133, 2010.

[11] I. Janotka and L. Krajči, "Utilization of natural zeolite in Portland pozzolan cement of increased sulfate resistance," in Proceedings of the 5th CANMET/ACI Conf. Durab. Concr., pp. 223-238, 2000.

[12] T. Perraki, G. Kakali, and F. Kontoleon, “The effect of natural zeolites on the early hydration of Portland cement," Microporous and Mesoporous Materials, vol. 61, no. 1-3, pp. 205-212, 2003.

[13] I. Janotka, A. Ray, and S. C. Mojumdar, "Acid and sulfate resistance of Portland cement - natural zeolite mortar," in Proceedings of 8th CANMET/ACI International Conference on Fly Ash, Silica Fume, Slag and Natural Pozzolans in Concrete, Las Vegas, pp. 639-652, 2004.

[14] R. Sersale and G. Frigione, "Natural zeolites as constituents of blended cements," Studies in Surface Science and Catalysis, vol. 24, pp. 523-530, 1985.

[15] T. Yun-Sheng, C. Huang, and K. Hsu, "The pozzolanic activity of a calcined waste FCC catalyst and its effect on the compressive strength of cementitious materials," Cement and Concrete Research, vol. 35, no. 4, pp. 782-787, 2005.

[16] B. Yılmaz, A. Uçar, B. Öteyaka, and V. Uz, "Properties of zeolitic tuff (clinoptilolite) blended portland cement," Building and Environment, vol. 42, no. 11, pp. 3808-3815, 2007.

[17] A. A. Ramezanianpour, R. Mousavi, M. Kalhori, J. Sobhani, and M. Najimi, "Micro and macro level properties of natural zeolite contained concretes," Construction and Building Materials, vol. 101, pp. 347-358, 2015.

[18] E. Vejmelková, D. Koňáková, T. Kulovaná et al., "Engineering properties of concrete containing natural zeolite as supplementary cementitious material: Strength, toughness, durability, and hygrothermal performance," Cement and Concrete Composites, vol. 55, pp. 259-267, 2015.

[19] C. S. Poon, L. Lam, S. C. Kou, and Z. S. Lin, "A study on the hydration rate of natural zeolite blended cement pastes," Construction and Building Materials, vol. 13, no. 8, pp. 427-432, 1999.

[20] V. J. Inglezakis and A. A. Zorpas, Handbook of Natural Zeolites, Cyprus Open University, 2012.

[21] D. Jana, "A new look to an old pozzolan, clinoptilolite A promising pozzolan in concrete," in Proceedings of the 29th ICMA Conference on Cement Microscopy, pp. 168-206, Quebec City, West Chester, 2007. 
[22] Y. Kasai, K. Tobinai, E. Asakura, and N. Feng, "Comparative study of natural zeolites and other inorganic admixtures in terms of characterization and properties of mortars," in Proceedings of the 9th Canmet/ACI Int. Conf. Fly Ash, Silica Fume, Slag Nat. Pozzolans Concr., V. D. Malhotra, Ed., pp. 615-634, 1992.

[23] N. Feng and H. Jia, "Prevention of AAR in cement concrete with natural zeolite," Concr. Cem. Prod, vol. 2, 1995.

[24] M. Najimi, J. Sobhani, B. Ahmadi, and M. Shekarchi, "An experimental study on durability properties of concrete containing zeolite as a highly reactive natural pozzolan," Construction and Building Materials, vol. 35, pp. 1023-1033, 2012.

[25] S. Y. N. Chan and X. Ji, "Comparative study of the initial surface absorption and chloride diffusion of high performance zeolite, silica fume and PFA concretes," Cement and Concrete Composites, vol. 21, no. 4, pp. 293-300, 1999.

[26] European Committee for Standardization, EN 196 -3 "Methods of Testing Cement - Part: Determination of Setting Times and Soundness, 2005, Brussels.

[27] European Committee for Standardization, EN 196 - 1, Methods of testing cement - Part 1: Determination of strength, Brussels, 2005.

[28] European Committee for Standardization, EN 15167-1, Ground granulated blast furnace slag for use in concrete, mortar and grout. Part 1: Definitions, specifications and conformity criteria, Brussels, 2007.

[29] European Committee for Standardization, EN 12390-7, Testing Hardened Concrete, part 7: Density of hardened concrete, Brussels, 2011.

[30] European Committee for Standardization, EN 12390-3, Testing Hardened Concrete, part 3: Compressive Strength of Test Specimens, Brussels, 2010.

[31] STN 731316 Determination of moisture, water absorption and capillarity of concrete, Slovak Office of Standards, Metrology and Testing, Bratislava, 1989.

[32] S. Özen, Pozzolanic activity of natural zeolites: mineralogical, chemical and physical characterization and examination of hydration products [Thesis], Middle East Technical University, 2013.

[33] F. Canpolat, K. Yılmaz, M. Köse, M. Sümer, and M. Yurdusev, "Use of zeolite, coal bottom ash and fly ash as replacement materials in cement production," Cement and Concrete Research, vol. 34, no. 5, pp. 731-735, 2004.

[34] T. Markiv, K. Sobol, M. Franus, and W. Franus, "Mechanical and durability properties of concretes incorporating natural zeolite," Archives of Civil and Mechanical Engineering, vol. 16, no. 4, pp. 554-562, 2016.

[35] T. R. Naik, "Concrete durability as influenced by density and/or porosity," Report No. CBU-1997-27, Center for By-Products Utilization, 1997.

[36] D. Nagrockiene and G. Girskas, "Research into the properties of concrete modified with natural zeolite addition," Construction and Building Materials, vol. 113, pp. 964-969, 2016.

[37] D. Nagrockiene, G. Girskas, and G. Skripkiūnas, "Properties of concrete modified with mineral additives," Construction and Building Materials, vol. 135, pp. 37-42, 2017.

[38] M. Valipour, M. Yekkalar, M. Shekarchi, and S. Panahi, "Environmental assessment of green concrete containing natural zeolite on the global warming index in marine environments," Journal of Cleaner Production, vol. 65, pp. 418-423, 2014. 

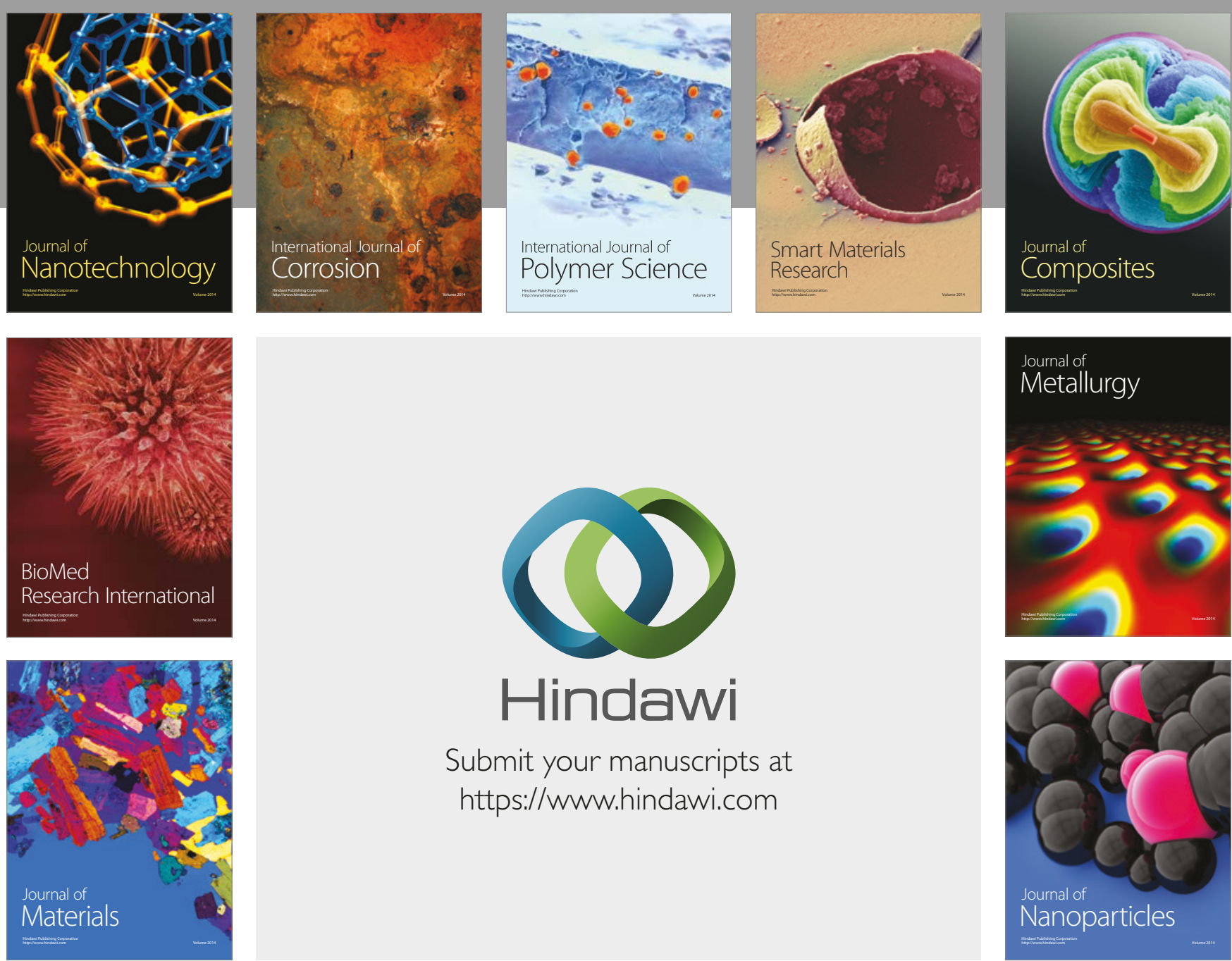

\section{Hindawi}

Submit your manuscripts at

https://www.hindawi.com
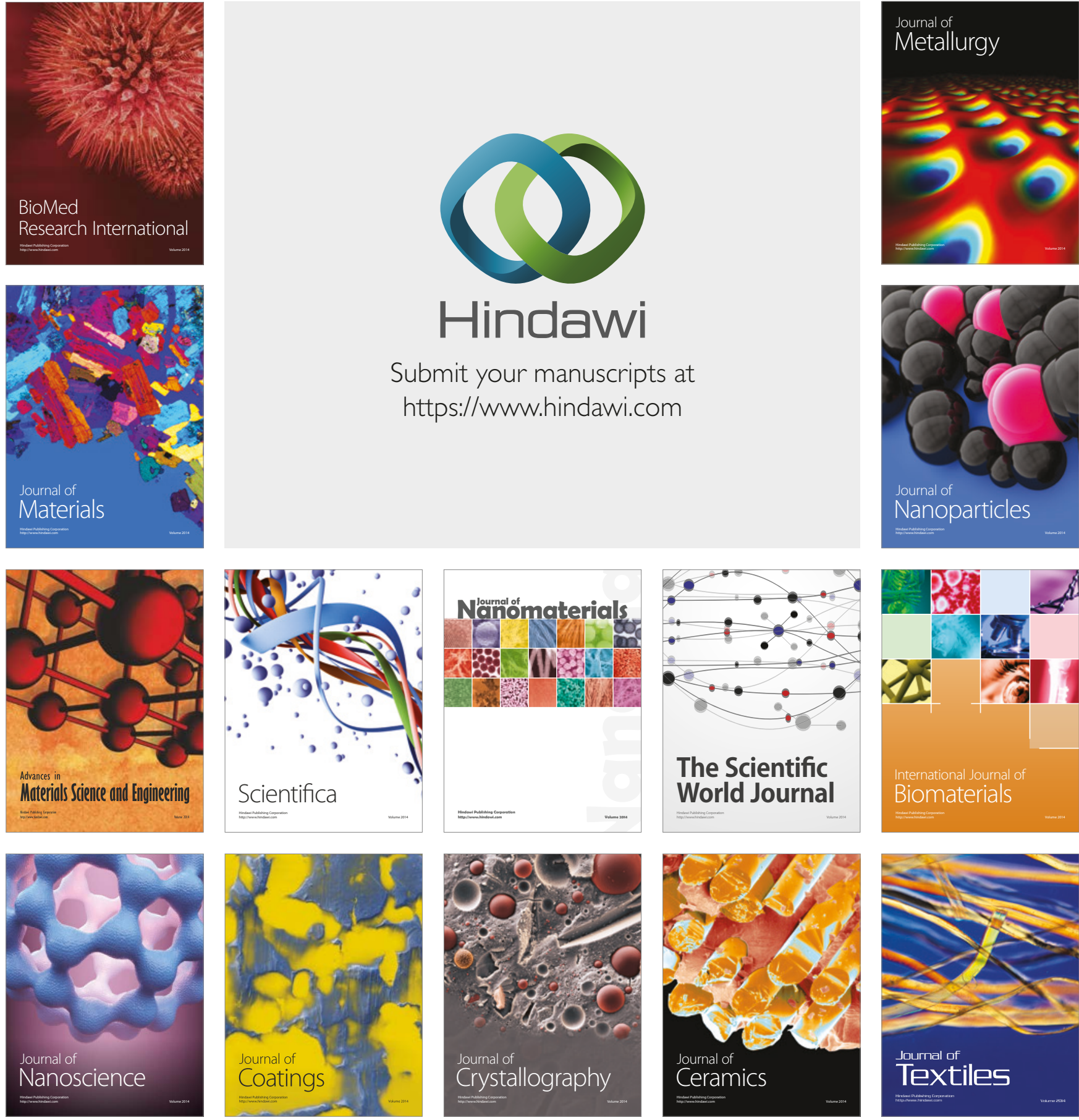

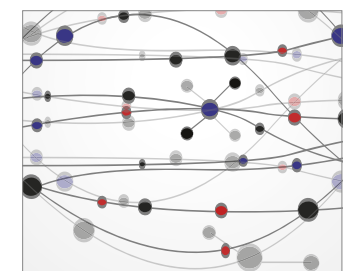

The Scientific World Journal
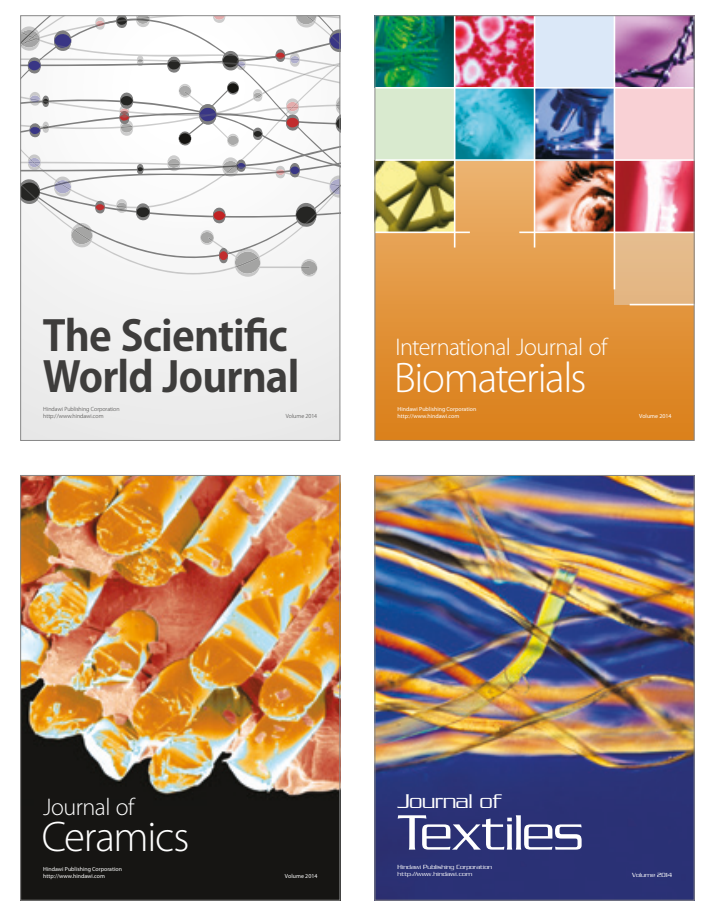